\title{
Social Media Usage Intensity and Academic Performance among Undergraduate Students in Saudi Arabia
}

\author{
Abdullah S. Alshalawi \\ University of Jeddah, College of Education, Department of Curriculum and Instruction, Jeddah, Saudi Arabia \\ ORCID: 0000-0003-0781-2004
}

Received: 22 Jul 2021

Accepted: 12 Nov 2021

\begin{abstract}
As the statistics show, use of social media networks (SMNs) are very common among college students worldwide. According to a report by Hootsuite, Saudi Arabia was ranked as the number-one country in the growth of social media users. With the advancement of technology and internet speed, investigating how SMNs affect students has become an absolute necessity. Therefore, the purpose of this study was to examine the influence of social media networks (SMNs) on the academic performance of undergraduate students across the Kingdom of Saudi Arabia, taking gender differences into account. An invitation email to participate in the online survey was sent to all undergraduate students at five public universities in Saudi Arabia. In total, 453 students from five public universities participated in this study. The results suggested that female students tend to spend more time on SMNs for general purposes and academic purposes than male students. In regard to multitasking with SMNs during schoolwork and social media usage intensity, the results showed no significant differences between male and female students. Finally, the regression analysis showed a positive relationship between students' academic performance and SMNs usage intensity after gender and high school GPA were controlled for.
\end{abstract}

Keywords: social media, learning performance, gender studies, mobile learning

\section{INTRODUCTION}

People are eager to try new technologies, and social media networks (SMNs) are among the popular internetbased technologies that attract many people (Manca \& Ranieri, 2016). Ellison (2007) defines SMNs as "webbased services that allow individuals to (1) construct a public or semi-public profile within a bounded system, (2) articulate a list of other users with whom they share a connection, and (3) view and traverse their list of connections and those made by others within the system" (p. 211). SMNs have attracted hundreds of millions of people, who make them a part of their daily lives and use them to connect with others based on their interests (Clarkson, 2012). Initially, SMNs were intended to be tools for socializing (Madge et al., 2009). However, people have expanded the uses of SMNs to areas such as business (Li et al., 2014), tourism (Gao et al., 2012), and education (Sánchez et al., 2014). SMNs are platforms that people join to be part of the networks, investigate their contents, build social and educational relationships, and share their experiences (Jiao et al., 2015).

According to a report by Hootsuite ("DIGITAL in 2020 "), there are 3.8 billion social media users around the world. Since January 2019, the number of social media users has increased by $9.2 \%$, with 321 million new users. As the statistics show, use of SMNs are very common among college students worldwide. For example, Fodah and Alajlan (2015) found that $99 \%$ of undergraduate students in Saudi Arabia are active SMNs users. 
The same Hootsuite report ranked Saudi Arabia as the number-one country in the growth of social media users. Saudi Arabia is experiencing rapid growth in information and communications technology (ICT) infrastructure. With this growth and expansion in ICT, SMNs usage is increasing. Saudi Arabia is one of the developing countries that allocates a significant portion of its budget to education. However, with the advancement of technology and internet speed, investigating how SMNs affect students has become an absolute necessity. In particular, the impact of SMNs use on academic performance needs to be studied. The purpose of this study is to determine how SMNs usage affects academic performance.

\section{LITERATURE REVIEW}

This growing phenomenon, SMNs usage among students, has inspired many educators in the past two decades to conduct research to investigate the potential influence that this new technology may have on educational outcomes (Glogocheski, 2015; Haddad, 2012; Junco, 2015; Karpinski et al., 2013; Kashif, 2013; Michikyan et al., 2015; Paul et al., 2012). As do any technologies that emerge, SMNs have advantages and disadvantages. One of the advantages that various studies have emphasized is that SMNs provide an additional space for students to collaborate and interact outside the classroom (Junco et al., 2012). However, one of the most obvious disadvantages that researchers have identified is that SMNs can waste a lot of students' time (Haddad, 2012).

Much research has been done worldwide to investigate the relationship between academic performance and the use of SMNs as whole or of one network in particular, such as Facebook. Most of these studies found a negative relationship between SMNs use and academic performance (Alam \& Aktar, 2021; Alexander, 2012; Ddungu et al., 2021; Ellis et al., 2010; Glass et al., 2013; Glogocheski, 2015; Haddad, 2012; Hyatt, 2011; Junco, 2015; Karpinski et al., 2013; Kashif, 2013; Michikyan et al., 2015; Paul et al., 2012; Raza et al., 2020; Skiera et al., 2015). For example, Karpinski et al. (2013) conducted a study to compare two samples from two different continents, one from the United States $(n=451)$ and the other from Europe $(n=406)$. They found a significant negative relationship between time spent on SMNs and students' GPAs in both samples, with the American sample being more significant. Moreover, Paul et al. (2012) surveyed 340 undergraduate students enrolled in business school courses in the United States. They concluded that students' academic performance was negatively influenced by time spent on SMNs. At a university in Finland, Kashif (2013) conducted a study on undergraduate students, and he also found a negative relationship between the use of Facebook and academic performance.

However, a few studies have found no relationship between the use of SMNs and academic performance (Ahmed \& Qazi, 2011; Alwagait et al., 2015; Hargittai \& Hsieh, 2010; Kabre \& Brown, 2011; Lubis et al., 2012). Alwagait et al. (2015) carried out an investigation to assess the relationship between time spent on SMNs and students' GPAs. They surveyed 104 students and found no linear relationship between them. Similarly, Kabre and Brown (2011) could not find a relationship between the number of hours spent on Facebook and academic performance. We were able to identify only two studies that found a positive relationship between students' academic performance and SMNs use (Ali et al., 2021; Ainin et al., 2015). Ainin et al. (2015) studied the impact of Facebook use on the academic performance of 1,165 Malaysian university students. They concluded that increased Facebook use is likely to have a positive influence on students' academic performance.

Gender has historically been an important factor in the communication and information technology divide (Alnjadat et al., 2019; Bain \& Rice, 2006; Cotten et al., 2009; Jackson et al., 2001; Kimbrough et al., 2013). Even though gender no longer plays a significant role in overall technology access and use, gender differences still exist in the use of particular types of modern technology and multitasking with schoolwork (Khan, 2017; Kimbrough et al., 2013; Kircaburun et al., 2020; Sheldon \& Bryant, 2016). For example, Kimbrough et al. (2013) conducted a study to investigate gender differences in the use of SMNs. They found that female undergraduate students use SMNs for educational purposes more than males. Alnjadat et al. (2019) found that male students were more addicted to SMNs than female students. Junco and Cotten (2012) found that males used mobile phones for recreational uses such as gaming, photos, and video more than females. 
Much of the previous research that considers SMN multitasking during schoolwork among undergraduate students has not focused on gender differences (Bowman et al., 2010; Junco \& Cotten, 2012; Karpinski et al., 2013; Lau, 2017). Research among middle school students has shown that gender influences multitasking behavior (Foehr, 2006; Rideout et al., 2010). Rideout et al. (2010) reported that female middle school students are more likely to report multitasking than males. The same finding was obtained by Foehr (2006) in a sample of 14 - to 16 -year-olds. This study makes a primary contribution by investigating the gender differences in multitasking with SMNs during schoolwork among undergraduate students.

Higher education in Saudi Arabia is unique, as K-12 and higher education are segregated by gender. According to the Ministry of Education, there are 27 public universities and 10 private universities for both genders and one university for females only. While many researchers have investigated the effect of SMNs on academic performance worldwide, only one study on the influence of SMNs in Saudi Arabia has been identified (Alwagait et al., 2015). The study did not provide much information about the participants, such as gender or level of education. A detailed study that pays attention to student characteristics known to influence the use of SMNs in Saudi Arabia is missing, and this study aims to bridge this gap in the extant literature. The scope of this paper is the influence of SMNs on academic performance among undergraduate students across the Kingdom of Saudi Arabia, taking gender differences and high school GPA into account.

\section{Social Capital}

In 1988, Coleman (1988) introduced the theory of social capital as he explored the influence of family, friends, and community on the individual. According to Coleman (1988), social capital describes the diverse resources that individuals gain from their interactions and relationships with others. These resources can be in the form of, for example, information, motivations, financial support, or norm. The term social capital often refers to the healthy resources that assist individuals in achieving desirable goals. The theory indicates that "just as physical capital and human capital facilitate productive activity, social capital does as well. For example, a group within which there is extensive trustworthiness and extensive trust is able to accomplish much more than a comparable group without that trustworthiness and trust" (Coleman, 1988, p. 101).

Many studies have found social capital to be a success factor for humans in various sectors. The theory suggests that families and communities who have healthy and supportive environments that enrich their members' social capital are more likely to produce successful individuals. In education, many researchers have examined the influence of social capital on educational outcomes (Bauer et al., 2007; Coleman, 1988; Dufur et al., 2013; Ellison et al., 2007; Lindfors et al., 2017; Sun, 1999; Unlusoy et al., 2013). Coleman (1988) studied the influence of family-student relationships and community-student relationships on academic performance. He concluded that students with strong social capital with their families and/or communities were less likely to drop out of school than those who had weak social capital.

In the past, obstacles such as time, location, and language have restricted interactions between people. The revolution of technology in the past few decades has enabled humans to tackle these obstacles and make more interactions possible. The internet, for example, facilitates new types of relationships among browsers and enables them to interact with others regardless of location. SMNs help to maintain and expand these interactions and relationships. Thus, these innovative technologies are useful tools for maintaining and increasing social capital. As Ellison et al. (2007) argued, some features of Facebook enable users to strengthen their weak ties with others, which in turn increases their social capital. On the other hand, the accessibility and usability of SMNs have led the current generation of students to spend a great deal of their time using SMNs, which in turn might affect the time they spend preparing for class and their academic performance in the long run. The MSNs is a real double-edged sword as claimed by Smith (2016). Thus, the purpose of this study was to examine the influence of SMNs on the academic performance of undergraduate students.

As discussed in the previous section, previous studies have found that some demographic variables are important to consider when examining SMNs use and academic performance. The objectives of this study are to (1) investigate gender differences in the use of SMNs and (2) examine the relationship between SMNs usage intensity and academic performance, taking gender differences and high school GPA (HSGPA) into account. The following research questions guided this study: 
1. Is there a gender difference in the time spent on SMNs for general purposes (TSMNG)?

2. Is there a gender difference in the time spent on SMNs for academic purposes (TSMNA)?

3. Is there a gender difference in multitasking (using SMNs during schoolwork) (MDS) and SMNs usage intensity (SMNUI)?

4. Is there a relationship between SMNs usage intensity and academic performance?

\section{SAMPLE DATA COLLECTION}

An invitation email to participate in the online survey was sent to all undergraduate students through the Deanship of Information Technology at five public universities in Saudi Arabia. One month later, a second reminder was sent. Data were collected in fall 2019. The sample consisted of 453 students.

\section{Instrumentation}

The independent variables were SMNs Usage Intensity (SMNUI), Multitasking During Schoolwork (MDS), Time spent on SMNs for General purposes (TSMNG), and Time spent on SMNs for Academic purposes (TSMNA). The dependent variable was academic performance. A pull-down menu on the survey was used to allow students to select the hours and minutes spent on SMNs for general purposes and the time spent on SMNs preparing for class. Academic performance was evaluated with a single item: The participants were required to provide their current GPAs. Because the first language of the participants was Arabic, the survey was translated into Arabic. The translation process involved bilingual reviewers and back-translation to make sure that both versions were equivalent.

\section{SMNs Usage Intensity}

The researcher adopted an existing instrument that has been used to measure SMSs usage intensity by many studies (Ainin et al., 2015; Ellison et al., 2007; Ross et al., 2009) and reflects high internal consistency (.87). For example, Ainin et al. (2015) used this instrument to measure Facebook usage intensity. The instrument consists of five items: "Social media networks are part of my everyday activity," "I feel I am part of the social media community," "I am proud to tell people I am using social media networks," "Social media networks have become part of my daily life," and "I would be upset if social media networks shut down." The participants were required to answer all the items using a 5-point Likert scale ranging from 1 strongly disagree to 5 strongly agree. Cronbach's alpha was used to assess the internal consistency of the SMNs intensity scale. the Cronbach's alpha for usage intensity in this study was .76.

\section{Multitasking}

To measure multitasking during schoolwork, the researcher used a scale developed by Lau (2017). The scale has been used in some studies and reflects high internal consistency. The scale consists of the following items: "I use social media in the classroom," "I open my social media accounts during the lecture," "I remain online with my social media site(s) while doing homework," and "I multitask with my social media account while studying." The items were rated on a 5 -point Likert-type scale $(5=$ never, $4=$ rarely, $3=$ sometimes, $2=$ often, $1=$ always).

\section{RESULTS}

\section{Descriptive Statistics}

Undergraduate students from five public Saudi universities participated in this study. Sixty percent of those who took the survey were male. The age of the participants ranged from 18 to 25 . Thirty-eight percent of students in the sample were freshmen, $25 \%$ were sophomores, $30 \%$ were juniors, and $7 \%$ were seniors. In terms of nationality, the majority (95\%) were Saudis. The demographics of the participants, particularly in relation to gender, age, and nationality, are quite representative of the undergraduate student population in 
Saudi public universities. The average HSGPA in the sample was 92.55 out of 100 (SD 6.8), and the average college GPA was 3.21 (SD 0.61).

As shown in Figure 1, Snapchat was the most popular app used for general purposes (33.1\%), followed by Twitter (22.3\%), WhatsApp (19.9\%), and Instagram (11.3\%). In terms of academic purposes, WhatsApp was the most used app among students (60.9\%), followed by YouTube (22.1\%) (see Figure 2). Table 1 provides the means and standard deviations of the study variables. Students spent an average time of 198 minutes (SD 86.19) per day on SMNs for general purposes and an average time of 74 minutes (SD 72.45) per day on SMNs for academic purposes.

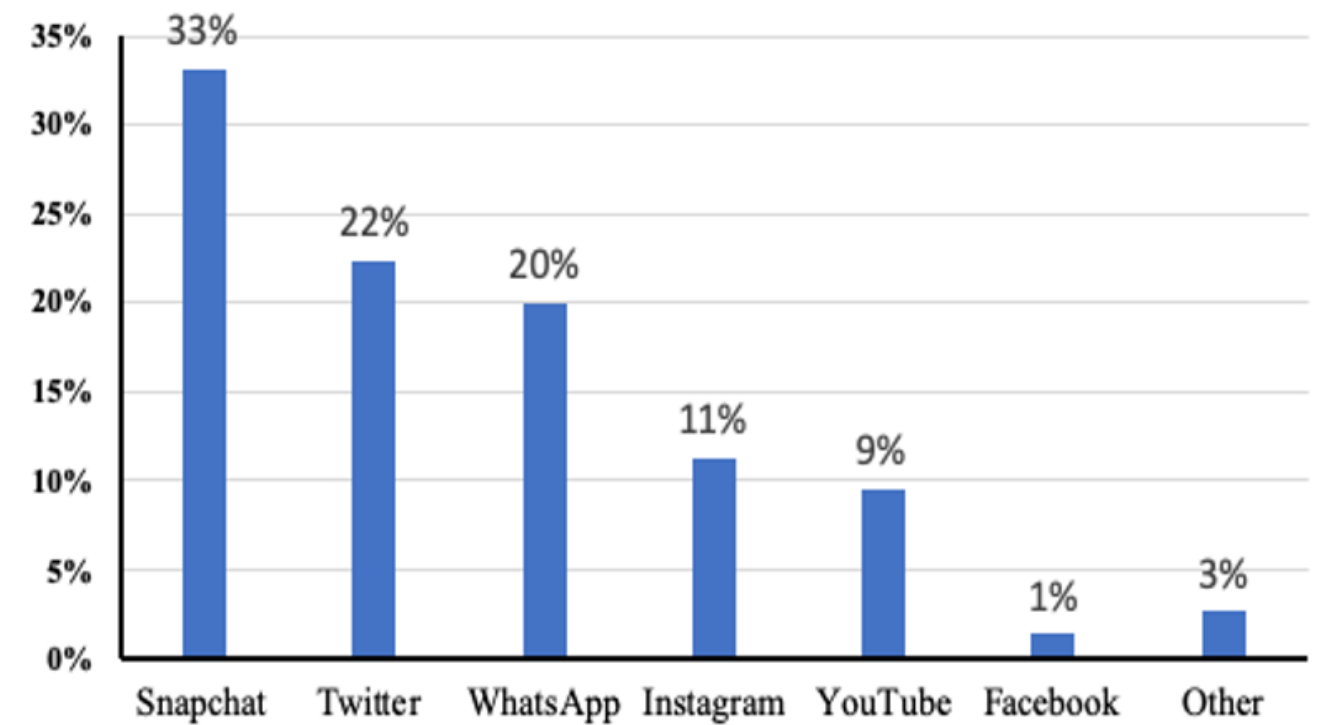

Figure 1. Most popular SMNs among students

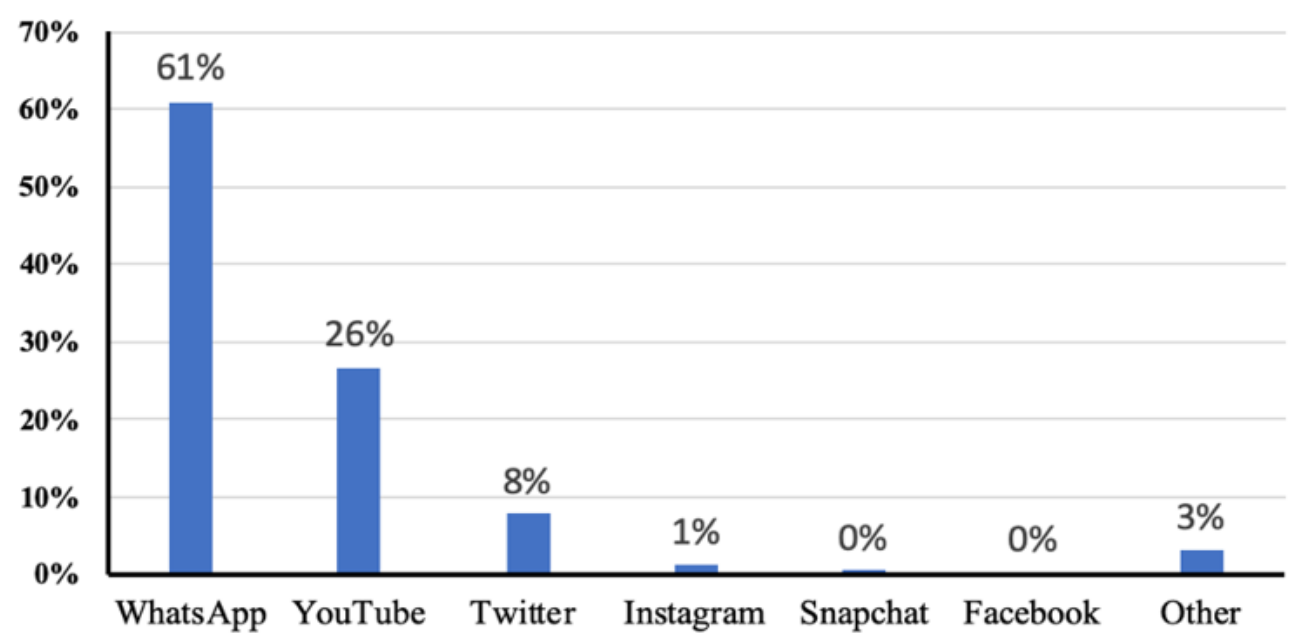

Figure 2. Most popular SMNs for academic purposes

Table 1. Descriptive and reliability statistics

\begin{tabular}{|c|c|c|c|}
\hline Variable & Reliability Cronbach's alphas & Mean & SD \\
\hline HSGPA & & 92.55 & 6.80 \\
\hline GPA & & 3.20 & 0.61 \\
\hline Time spent on SMN for general purposes & & $197 \mathrm{~min}$ & 86.19 \\
\hline Time spent on SMN for academic purposes & & $73 \mathrm{~min}$ & 72.54 \\
\hline Time spent preparing for class & & $116 \mathrm{~min}$ & 112.23 \\
\hline SMNUI & 0.78 & 2.05 & 0.65 \\
\hline MDS & 0.84 & 3.19 & 0.91 \\
\hline
\end{tabular}

$\mathrm{N}=453$ 
Cronbach's alpha was used to assess the internal consistency of the SMNs intensity scale and multitasking scale. As presented in Table 1, the Cronbach's alpha for usage intensity was .76 and .84 for multitasking. The scores for the SMNs usage intensity (SMNUI) scale were determined using a 5-point Likert-type scale $(5=$ strongly disagree, $4=$ disagree, $3=$ neutral, 2 = agree, $1=$ strongly agree), with the negative item reversecoded. The mean was 2.44 (SD = .98), which fell between neutral (3) and agree (2). For the multitasking scale (MDS), the items were rated on a 5-point Likert-type scale (5-never, 4-rarely, 3-sometimes, 2-often, 1-always), with the negative item reverse-coded.

The mean fell close to sometimes $(m=3.19, S D=0.9)$. Table 2 presents the correlation matrix for the study's variables.

\section{Time Spent on SMNs for General Purposes}

Question 1: Is there a gender difference in the time spent on SMNs for general purposes?

A comparison of time spent on SMNs for general purposes was made based on gender, using a t-test. As presented in Table 2, the results revealed that there was a significant difference in time spent on SMNs for general purposes $(t(451)=-2.86, P<.001)$. Female students $(M=212.15, S D=81.54)$ tend to spend more time on SMNs for general purposes than male students $(M=188.94, S D=88.2)$.

Table 2. Correlation matrix for the study's variables

\begin{tabular}{|c|c|c|c|c|c|c|}
\hline & HSGPA & GPA & TSMNG & TSMNA & MDS & SMNUI \\
\hline HSGPA & & $.348^{* *}$ & .025 & $.180 * *$ & -.089 & -.033 \\
\hline GPA & & & -.043 & $.122^{* *}$ & -.025 & .081 \\
\hline TSMNG & & & & $.200 * *$ & $-.160 * *$ & $-.285^{* *}$ \\
\hline TSMNA & & & & & -.043 & -.054 \\
\hline MDS & & & & & & $.456 * *$ \\
\hline SMNUI & & & & & & \\
\hline
\end{tabular}

\section{Time Spent on SMNs for Academic Purposes}

Question 2: Is there a gender difference in the time spent on SMNs for academic purposes?

With respect to the time spent on SMNs for academic purposes, a t-test was used to compare the means of the two groups. The analysis showed a significant difference in time spent on SMNs for academic purposes between male and female students $(t(451)=-5.39, P<.001)$ (see Table 3$)$. Female students $(M=95.74, S D$ $=80.9)$ tend to spend more time on SMNs for academic purposes on a daily basis than male students $(\mathrm{M}=$ 95.19, SD = 26.28).

\section{Gender, Multitasking, and Social Media Usage Intensity}

Question 3: Is there a gender difference in multitasking (using SMNs during schoolwork) and SMNs usage intensity?

Table 3 shows the means of the frequency of multitasking and SMNs usage intensity for male and female students. The results of the t-tests show no significant differences between male and female students in multitasking with SMNs during schoolwork $(\mathrm{t}(451)=.969, \mathrm{P}>.05)$ or SMNs usage intensity $(\mathrm{t}(451)=1.94, \mathrm{P}$ $>$.05).

Table 3. Gender differences in SMN usage

\begin{tabular}{|c|c|c|c|c|c|c|}
\hline \multirow{2}{*}{ Variable } & \multicolumn{2}{|c|}{ Female } & \multicolumn{2}{|c|}{ Male } & \multirow{2}{*}{$t(d f)$} & \multirow{2}{*}{$p$-value } \\
\hline & $M$ & SD & $M$ & SD & & \\
\hline TSMNG (General) & 212.15 & 81.54 & 188.94 & 88.02 & $-2.86(451)^{* *}$ & .004 \\
\hline TSMNA (Academic) & 95.47 & 80.9 & 59.19 & 26.28 & $-5.39(451)^{* * *}$ & .000 \\
\hline MDS & 3.15 & .93 & 3.23 & .90 & .969 (451) & .333 \\
\hline SMNUI & 1.98 & .60 & 2.10 & .69 & $1.94(451)$ & .217 \\
\hline
\end{tabular}

$\mathrm{N}=453 .^{*} \mathrm{p}<.05, * * \mathrm{p}<.01, * * * \mathrm{p}<.001$ 


\section{SMN Usage Intensity and Academic Performance}

Question 4: Is there a relationship between SMNs usage intensity and academic performance?

Hierarchical regression analysis was used to answer this question. Hierarchical regression is a statistical analysis procedure used to determine if the independent variables explain a statistically significant amount of variance in the dependent variable after other variables are accounted for. Gender and HSGPA were entered as the control variables in the first and second blocks. Gender is a nominal variable that cannot be entered directly in a multiple regression analysis. Dummy-variable coding was used to translate nominal data into quantitative data for use in the regression analysis (Cohen et al., 2003). In this study, gender was coded as 1 for male and 0 for female. The data of this study satisfied all six assumptions of multiple regression analysis and multicollinearity.

The hierarchical linear regression predicting overall GPA $\left(F=25.059, p<.001, R^{2}=.143\right)$ was significant (see Table 3). In block 1, gender was significantly related to GPA $\left(F=11.162, p<.01, R^{2}=.024\right)$. Male students had lower GPAs than female students. In block 2, HSGPA was added. The results remained the same as in block 1 in terms of gender, and HSGPA was significantly associated with GPA $\left(F=34.468, p<.001, R^{2}=.024\right)$.

As shown in Table 4, SMNs usage intensity was entered in block 3. The results indicated that SMNs usage intensity had a significant effect on students' GPAs $\left(F=25.059, p<.001, R^{2}=.143\right)$. The results remained the same as in block 2 in terms of gender and HSGPA. Of particular interest was the finding of block 3: SMNs usage intensity was found to be a strong predictor of students' GPAs and explained a significant amount of the variance in the dependent variable.

Table 4. Hierarchical regression model exploring how SMNUI predicts overall GPA ( $N=453)$, after controlling for gender and HSGPA

\begin{tabular}{lccc}
\hline Independent variables & Block 1 $(\beta)$ & Block 2 $(\beta)$ & Block 3 $(\beta)$ \\
\hline Gender (male) & $-.155^{* *}$ & $-.105^{*}$ & $-.118^{* *}$ \\
HSGPA & & $.333^{*}$ & $.335^{* * *}$ \\
SMNUI & & & $.103^{*}$ \\
Adjusted R & $.022^{* * *}$ & $.129^{* * *}$ & $.138^{* * *}$ \\
\hline$\beta=$ Befa
\end{tabular}

$\beta=$ Beta, the standardized regression coefficient. ${ }^{*} p<.05,{ }^{* *} p<.01,{ }^{* * *} p<.001$.

\section{DISCUSSION}

This study concerns how SMNs influence academic performance, taking gender differences into account. The main research questions were as follows: (1) Is there a gender difference in the time spent on SMNs for general purposes? (2) Is there a gender difference in the time spent on SMNs for academic purposes? (3) Is there a gender difference in multitasking (using SMNs during schoolwork) and SMNs usage intensity? (4) Is there a relationship between SMNs usage intensity and academic performance? SMNs seem to have permeated the everyday lives of undergraduate students in Saudi Arabia. Students who participated in our study spent an average of about three and a half hours a day on SMNs for general purposes. Students also reported spending almost two hours a day on SMNs for academic purposes. Thus, the total time that undergraduate students spend on SMNs daily is about six hours. Snapchat and Twitter were the first and second most commonly used social media platforms among students for general purposes, and WhatsApp and YouTube were the most commonly used for academic purposes.

With regard to gender differences, the results showed a significant association between gender and time spent on SMNs for both academic and general purposes. Female students tend to spend more time on SMNs for general purposes and academic purposes than male students. The difference found in this study can be attributed to the culture and social differences associated with female students in Saudi Arabia, where females generally tend to spend more time at home. Thus, they stay in touch with their relatives, classmates, and friends through SMNs.

This finding is consistent with previous studies, which suggest that women spend more time on SMNs to share, view, comment, and reply than men (Choi et al., 2017; Khan, 2017; Kircaburun et al., 2020; Rideout et 
al., 2010; Sheldon \& Bryant, 2016; Sorokowski et al., 2016). In terms of academic purposes, Ali et al. (2021), Horzum (2016), and Kimbrough et al. (2013) found that women use SMNs for educational purposes more than men. Contrary to this study's findings, Alnjadat et al. (2019), Bauman et al. (2013), and Kasahara et al. (2019) found that male students tend to spend more time using SMNs than female students.

Multitasking with SMNs during schoolwork did not significantly differ by gender, according to the t-test. There is limited research on multitasking during schoolwork for undergraduate students that considers gender differences. Therefore, it is not possible to compare this result to previous studies. However, it is possible to compare this result with studies that consider gender differences in SMN multitasking with other tasks. For example, this finding is consistent with that of Ophir et al. (2009) but contradicts other multitasking studies, such as Foehr's (2006) and Jeong and Fishbein's (2007). Foehr (2006) found that females tend to multitask with media more than males. Even though the findings of this study showed gender differences in time spent using SMNs, there was no gender difference in multitasking behavior. In general, the findings are consistent with previous findings showing greater use of SMNs by females.

In regard to research question four, the results showed a positive relationship between students' academic performance and SMNs usage intensity (i.e., the higher the usage, the better they performed). This finding is in agreement with the studies by Ali et al. (2021) and Ainin et al. (2015). However, it contradicts most past studies, which have reported that higher usage of SMNs results in lower academic performance (Alam \& Aktar, 2021; Ddungu et al., 2021; Ellis et al., 2010; Gabre \& Kumar, 2012; Junco, 2015; Junco \& Cotten, 2012; Karpinski et al., 2013; McLoughlin \& Lee, 2010; Raza et al., 2020; Tess, 2013; Wohn \& LaRose, 2014) and other studies that reported no effect on students' performance (Ahmed \& Qazi, 2011; Alwagait et al., 2015; Hargittai \& Hsieh, 2010; Kabre \& Brown, 2011; Lubis et al., 2012).

A plausible explanation for this result can be explained by the social capital theory. For illustration, SMNs are tools that help students maintain and increase social capital, which in turn positively influence their performance as many researchers have found that (Dufur et al., 2013; Ellison et al., 2007; Lindfors et al., 2017; Sun, 1999; Unlusoy et al., 2013). These contradictions in the literature could be due to some other factors (e.g., the inability to understand SMN complexities, the different purposes that students use SMNs for, or cultural differences).

\section{CONCLUSIONS}

This study examined the gender differences in SMN use and the relationship between SMN usage intensity and academic performance among undergraduate students in Saudi Arabia. It found that female students tend to spend more time on SMNs for general purposes and academic purposes than male students. It also found that multitasking did not significantly differ by gender. Finally, after gender and HSGPA were controlled for, the regression analysis showed a positive relationship between students' academic performance and SMNs usage intensity. This finding contradicts most of the previous studies, which were conducted in different countries, as indicated in the discussion.

This study has several limitations. First, the results of the analysis in this study represents only the trends observed during that period of time. Second, the sample used in this study was limited to five public universities in Saudi Arabia. Thus, the findings of the study cannot be generalized to other universities. Finally, this study used self-report measures. Future research may consider another approach to examine the influence of SMNs on academic performance. Moreover, future research may consider examining the influence of social media networks usage intensity on academic performance, taking purposes of usage, type of social media networks, and cultural differences into account.

Funding: This work was funded by the University of Jeddah, Saudi Arabia, under grant No. (UJ-20-DR 68). The author, therefore, acknowledge with thanks the University technical and financial support.

Declaration of interest: Author declares no competing interest.

Data availability: Data generated or analysed during this study are available from the author on request. 


\section{REFERENCES}

Ahmed, I., \& Qazi, T. F. (2011). A look out for academic impacts of Social Networking Sites (SNSs): A student based perspective. African Journal of Business Management, 5(12), 5022-5031. https://doi.org/10.5897/AJBM11.595

Ainin, S., Naqshbandi, M. M., Moghavvemi, S., \& Jaafar, N. I. (2015). Facebook usage, socialization and academic performance. Computers and Education, 83, 64-73. https://doi.org/10.1016/j.compedu. 2014.12.018

Alam, M. S., \& Aktar, H. (2021). The effect of social media on student academic performance: A case study at the Islamic University of Bangladesh. International Journal on Transformations of Media, Journalism \& Mass Communication, 6(1), 26-44.

Alexander, C. M. (2012). Facebook usage and academic achievement of high school students: A quantitative analysis [PhD Thesis, Pepperdine University].

Ali, S., Qamar, A., Habes, M., \& Al Adwan, M. N. (2021). Gender discrepancies concerning social media usage and its influences on students academic performance. Utopía y praxis latinoamericana: revista internacional de filosofía iberoamericana y teoría social [Latin American Utopia and Praxis: International Journal of Ibero-American Philosophy and Social Theory], 26(1), 321-333. https://doi.org/10.5281/zenodo.4556283

Alnjadat, R., Hmaidi, M. M., Samha, T. E., Kilani, M. M., \& Hasswan, A. M. (2019). Gender variations in social media usage and academic performance among the students of University of Sharjah. Journal of Taibah University Medical Sciences, 14(4), 390-394. https://doi.org/10.1016/j.jtumed.2019.05.002

Alwagait, E., Shahzad, B., \& Alim, S. (2015). Impact of social media usage on students academic performance in Saudi Arabia. Computers in Human Behavior, 51, 1092-1097. https://doi.org/10.1016/j.chb.2014.09. 028

Bain, C. D., \& Rice, M. L. (2006). The influence of gender on attitudes, perceptions, and uses of technology. Journal of Research on Technology in Education, 39(2), 119-132. https://doi.org/10.1080/15391523. 2006.10782476

Bauer, T. N., Bodner, T., Erdogan, B., Truxillo, D. M., \& Tucker, J. S. (2007). Newcomer adjustment during organizational socialization: A meta-analytic review of antecedents, outcomes, and methods. Journal of Applied Psychology, 92(3), 707-721. https://doi.org/10.1037/0021-9010.92.3.707

Bauman, S., Toomey, R. B., \& Walker, J. L. (2013). Associations among bullying, cyberbullying, and suicide in high school students. Journal of Adolescence, 36(2), 341-350. https://doi.org/10.1016/j.adolescence. 2012.12.001

Bowman, L. L., Levine, L. E., Waite, B. M., \& Gendron, M. (2010). Can students really multitask? An experimental study of instant messaging while reading. Computers \& Education, 54(4), 927-931. https://doi.org/10.1016/j.compedu.2009.09.024

Choi, T. R., Sung, Y., Lee, J., \& Choi, S. M. (2017). Get behind my selfies: The big five traits and social networking behaviors through selfies. Personality and Individual Differences, 109, 98-101. https://doi.org/10.1016/j.paid.2016.12.057

Clarkson, K. (2012). Usage of social network sites amongst university students. GRIN Verlag.

Coleman, J. S. (1988). Social capital in the creation of human capital. American Journal of Sociology, 94, 95120. https://doi.org/10.1086/228943

Cotten, S. R., Anderson, W. A., \& Tufekci, Z. (2009). Old wine in a new technology, or a different type of digital divide? New Media \& Society, 11(7), 1163-1186. https://doi.org/10.1177/1461444809342056 
Ddungu, R. M., Nakijoba, R., Awobamise, A., \& Merab, A. (2021). Assessment of social media's influence on the academic performance of tertiary intuition student. Annals of Spiru Haret University. Economic Series, 21(3), 167-190.

DIGITAL in 2020. (2020). New York: HOOTSUITE. https://wearesocial.com/digital-2020

Dufur, M. J., Parcel, T. L., \& Troutman, K. P. (2013). Does capital at home matter more than capital at school? Social capital effects on academic achievement. Research in Social Stratification and Mobility, 31, 121. https://doi.org/10.1016/j.rssm.2012.08.002

Ellis, Y., Daniels, B., \& Jauregui, A. (2010). The effect of multitasking on the grade performance of business students. Research in Higher Education Journal, 8.

Ellison, N. B., Steinfield, C., \& Lampe, C. (2007). The benefits of Facebook "friends:" Social capital and college students' use of online social network sites. Journal of Computer-Mediated Communication, 12(4), 1143-1168. https://doi.org/10.1111/j.1083-6101.2007.00367.x

Fodah, O., \& Alajlan, H. (2015). A work in progress survey on mobile learning in higher education in Saudi Arabia. In D. Rutledge \& D. Slykhuis (Eds.), Proceedings of SITE 2015--Society for Information Technology \& Teacher Education International Conference (pp. 3591-3596). Las Vegas, NV, United States: Association for the Advancement of Computing in Education (AACE).

Foehr, U. G. (2006). Media multitasking among American youth: Prevalence, predictors and pairings. Henry J. Kaiser Family Foundation. https://www.kff.org/other/media-multitasking-among-american-youthprevalence-predictors/

Gabre, H., \& Kumar, G. (2012). The effects of perceived stress and Facebook on accounting students' academic performance. Accounting and Finance Research, 1(2), 87-100. https://doi.org/10.5430/afr. v1n2p87

Gao, F., Luo, T., \& Zhang, K. (2012). Tweeting for learning: A critical analysis of research on microblogging in education published in 2008-2011. British Journal of Educational Technology, 43(5), 783-801. https://doi.org/10.1111/j.1467-8535.2012.01357.x

Glass, R., Prichard, J., Lafortune, A., \& Schwab, N. (2013). The influence of personality and Facebook use on student academic performance. Issues in Information Systems, 14(2), 119-126.

Glogocheski, S. W. (2015). Social media usage and its impact on grade point average and retention: An exploratory study to generate viable strategies in a dynamic higher education learning environment [PhD Thesis, St. John's University].

Haddad, M. (2012). Correlation between minutes spent on Facebook and students' GPA. https://www. marwanhaddad.com/uploads/8/7/3/6/8736941/524_marwan_haddad_research_purposal.pdf

Hargittai, E., \& Hsieh, Y. P. (2010). Predictors and consequences of differentiated practices on social network sites. Information, Communication \& Society, 13(4), 515-536. https://doi.org/10.1080/1369118100363 9866

Horzum, M. B. (2016). Examining the relationship to gender and personality on the purpose of Facebook usage of Turkish university students. Computers in Human Behavior, 64, 319-328. https://doi.org/10.1016/j.chb.2016.06.010

Hyatt, R. Y. (2011). The influence of time spent by students engaged in co-curricular involvement, online social networking and studying and doing coursework on their academic achievement [Phd Thesis, University of South Florida]. https://www.semanticscholar.org/paper/The-influence-of-time-spentby-students-engaged-in-Hyatt/bdd2e73dfc3006283faf3fc322a3bda44a7e69d4 
Jackson, L. A., Ervin, K. S., Gardner, P. D., \& Schmitt, N. (2001). Gender and the Internet: Women communicating and men searching. Sex Roles, 44(5-6), 363-379. https://doi.org/10.1023/A:101093 7901821

Jeong, S., \& Fishbein, M. (2007). Predictors of multitasking with media: Media factors and audience factors. Media Psychology, 10(3), 364-384. https://doi.org/10.1080/15213260701532948

Jiao, Y., Gao, J., \& Yang, J. (2015). Social value and content value in social media: Two ways to flow. Journal of Advanced Management Science, 3(4), 299-306. https://doi.org/10.12720/joams.3.4.299-306

Junco, R. (2015). Student class standing, Facebook use, and academic performance. Journal of Applied Developmental Psychology, 36, 18-29. https://doi.org/10.1016/j.appdev.2014.11.001

Junco, R., \& Cotten, S. R. (2012). No A 4 U: The relationship between multitasking and academic performance. Computers \& Education, 59(2), 505-514. https://doi.org/10.1016/j.compedu.2011.12.023

Junco, R., Elavsky, C. M., \& Heiberger, G. (2012). Putting twitter to the test: Assessing outcomes for student collaboration, engagement and success. British Journal of Educational Technology, 44(2), 273-287. https://doi.org/10.1111/j.1467-8535.2012.01284.x

Kabre, F., \& Brown, U. J. (2011). The influence of Facebook usage on the academic performance and the quality of life of college students. Journal of Media and Communication Studies, 3(4), 144-150.

Karpinski, A. C., Kirschner, P. A., Ozer, I., Mellott, J. A., \& Ochwo, P. (2013). An exploration of social networking site use, multitasking, and academic performance among united states and European university students. Computers in Human Behavior, 29(3), 1182-1192. https://doi.org/10.1016/j.chb.2012.10.011

Kasahara, G. M., Houlihan, D., \& Estrada, C. (2019). Gender differences in social media use and cyberbullying in Belize: A preliminary report. International Journal of Psychological Studies, 11(2), 32-41. https://doi.org/10.5539/ijps.v11n2p32

Kashif, M. (2013). Impact of Facebook on students' academic performance [Master Thesis, University of Eastern Finland].

Khan, M. L. (2017). Social media engagement: What motivates user participation and consumption on YouTube? Computers in Human Behavior, 66, 236-247. https://doi.org/10.1016/j.chb.2016.09.024

Kimbrough, A. M., Guadagno, R. E., Muscanell, N. L., \& Dill, J. (2013). Gender differences in mediated communication: Women connect more than do men. Computers in Human Behavior, 29(3), 896-900. https://doi.org/10.1016/j.chb.2012.12.005

Kircaburun, K., Alhabash, S., Tosuntas, S. B., \& Griffiths, M. D. (2020). Uses and gratifications of problematic social media use among university students: A simultaneous examination of the big five of personality traits, social media platforms, and social media use motives. International Journal of Mental Health and Addiction, 18(3), 525-547. https://doi.org/10.1007/s11469-018-9940-6

Lau, W. W. (2017). Effects of social media usage and social media multitasking on the academic performance of university students. Computers in Human Behavior, 68, 286-291. https://doi.org/10.1016/j.chb. 2016.11.043

Li, G., Liu, H., \& Li, G. (2014). Payment willingness for VIP subscription in social networking sites. Journal of Business Research, 67(10), 2179-2184. https://doi.org/10.1016/j.jbusres.2014.04.028

Lindfors, P., Minkkinen, J., Rimpel, A., \& Hotulainen, R. (2017). Family and school social capital, school burnout and academic achievement: A multilevel longitudinal analysis among Finnish pupils. International Journal of Adolescence and Youth, 23(3), 368-381. https://doi.org/10.1080/02673843.2017.1389758 
Lubis, S. H., Ridzuan, S., Ishak, I. Y., Othman, H. F., Mohammed, N., Abdul Hamid, Z., Akmal, N.N., Norazizah, Farahana, N., Shahida, Shanti, Zafirah, N., Hui, L. L., \& Izham, M. (2012). The relationship between time spent on facebook and cumulative grade point average (CGPA) among third year biomedical science students in faculty health sciences, UKM. Procedia-Social and Behavioral Sciences, 60, 590-595. https://doi.org/10.1016/j.sbspro.2012.09.427

Madge, C., Meek, J., Wellens, J., \& Hooley, T. (2009). Facebook, social integration and informal learning at university: 'It is more for socialising and talking to friends about work than for actually doing work'. Learning, Media and Technology, 34(2), 141-155. https://doi.org/10.1080/17439880902923606

Manca, S., \& Ranieri, M. (2016). Facebook and the others. Potentials and obstacles of social media for teaching in higher education. Computers \& Education, 95, 216-230. https://doi.org/10.1016/ j.compedu.2016.01.012

McLoughlin, C., \& Lee, M. J. (2010). Personalised and self regulated learning in the Web 2.0 era: International exemplars of innovative pedagogy using social software. Australasian Journal of Educational Technology, 26(1), 28-43. https://doi.org/10.14742/ajet.1100

Michikyan, M., Subrahmanyam, K., \& Dennis, J. (2015). Facebook use and academic performance among college students: A mixed-methods study with a multi-ethnic sample. Computers in Human Behavior, 45, 265-272. https://doi.org/10.1016/j.chb.2014.12.033

Unlusoy, A., De Haan, M., Leander, K., \& Volker, B. (2013). Learning potential in youth's online networks: A multilevel approach. Computers \& Education, 68, 522-533. https://doi.org/10.1016/j.compedu.2013.06.007

Ophir, E., Nass, C., \& Wagner, A. D. (2009). Cognitive control in media multitaskers. Proceedings of the National Academy of Sciences, 106(37), 15583-15587. https://doi.org/10.1073/pnas.0903620106

Paul, J. A., Baker, H. M., \& Cochran, J. D. (2012). Effect of online social networking on student academic performance. Computers in Human Behavior, 28(6), 2117-2127. https://doi.org/10.1016/j.chb.2012.06.016

Raza, M. Y., Khan, A. N., Khan, N. A., Ali, A., \& Bano, S. (2020). Dark side of social media and academic performance of public sector schools students: Role of parental school support. Journal of Public Affairs, 20(3), e2058. https://doi.org/10.1002/pa.2058

Rideout, V. J., Foehr, U. G., \& Roberts, D. F. (2010). Generation $M^{2}$ : Media in the lives of 8-to 18-year-olds. Henry J. Kaiser Family Foundation. https://files.eric.ed.gov/fulltext/ED527859.pdf

Ross, C., Orr, E. S., Sisic, M., Arseneault, J. M., Simmering, M. G., \& Orr, R. R. (2009). Personality and motivations associated with Facebook use, Computers in Human Behavior, 25(2), 578-586. https://doi.org/10.1016/j.chb.2008.12.024

Sánchez, R. A., Cortijo, V., \& Javed, U. (2014). Students' perceptions of Facebook for academic purposes. Computers \& Education, 70, 138-149. https://doi.org/10.1016/j.compedu.2013.08.012

Sheldon, P., \& Bryant, K. (2016). Instagram: Motives for its use and relationship to narcissism and contextual age. Computers in Human Behavior, 58, 89-97. https://doi.org/10.1016/j.chb.2015.12.059

Skiera, B., Hinz, O., \& Spann, M. (2015). Social media and academic performance: Does the intensity of Facebook activity relate to good grades. Schmalenbach Business Review, 67, 54-72. https://doi.org/10.1007/BF03396923

Smith, E. E. (2016). "A real double-edged sword:" Undergraduate perceptions of social media in their learning. Computers \& Education, 103, 44-58. https://doi.org/10.1016/j.compedu.2016.09.009 
Sorokowski, P., Sorokowska, A., Frackowiak, T., Karwowski, M., Rusicka, I., \& Oleszkiewicz, A. (2016). Sex differences in online selfie posting behaviors predict histrionic personality scores among men but not women. Computers in Human Behavior, 59, 368-373. https://doi.org/10.1016/j.chb.2016.02.033

Sun, Y. (1999). The contextual effects of community social capital on academic performance. Social Science Research, 28(4), 403-426. https://doi.org/10.1006/ssre.1999.0661

Tess, P. A. (2013). The role of social media in higher education classes (real and virtual)-A literature review. Computers in Human Behavior, 29(5), A60-A68. https://doi.org/10.1016/j.chb.2012.12.032

Wohn, D. Y., \& LaRose, R. (2014). Effects of loneliness and differential usage of Facebook on college adjustment of first-year students. Computers \& Education, 76, 158-167. https://doi.org/10.1016/j.compedu.2014.03.018

Correspondence: Abdullah S. Alshalawi, University of Jeddah, College of Education, Department of Curriculum and Instruction, Jeddah, Saudi Arabia. E-mail: Aalshalwey@uj.edu.sa 